\title{
RESEARCH
}

Open Access

\section{Bitcoin pricing: impact of attractiveness variables}

\author{
Rodrigo Hakim das Neves(D)
}

\author{
Correspondence: rodrigohakim@ \\ hotmail.com \\ Sao Paulo School Of Economics \\ (FGV), Sao Paulo, Brazil
}

\begin{abstract}
The research seeks to contribute to Bitcoin pricing analysis based on the dynamics between variables of attractiveness and the value of the digital currency. Using the error correction model, the relationship between the price of the virtual currency, Bitcoin, and the number of Google searches that used the terms bitcoin, bitcoin crash and crisis between December 2012 and February 2018 is analyzed. The study also applied the same analysis to prices of Bitcoin denominated in different sovereign currencies traded during the same period. The Johansen (J Econ Dyn Control 12:231254,1988 ) test demonstrates that the price and number of searches on Google for the first two terms are cointegrated. This research indicates that there are strong short-term and long-term dynamics among attractiveness factors, suggesting that an increase in worldwide interest in Bitcoin is usually preceded by a price increase. In contrast, an increase in market mistrust over a collapse of the currency, as measured by the term bitcoin crash, is followed by a fall in price. Intense world economic crisis events appear to have a strong impact on interest in the virtual currency. This study demonstrates that during a worldwide crisis Bitcoin becomes an alternative investment, increasing its price. Based on it, bitcoin may be used as a safe haven by the financial market and its intrinsic characteristics might help the investors and governments to find new mechanisms to deal with monetary transactions.
\end{abstract}

Keywords: Bitcoin pricing, Price variables, Crisis

\section{Introduction}

Concurrent with a rapid price appreciation, the increase in financial market interest in digital currencies and in Bitcoin in particular, as well as global integration of virtual networks, have prompted the emergence of new academic studies related to economic behavior of this new asset that has been inserted in the world financial market.

Factors that make the asset extremely volatile to information and market variables include the absence of a centralized institution that controls and guarantees the value of Bitcoin and the understanding that its price is based on the belief that the virtual currency will continue its upward trajectory. It seems that there are yet opportunities to get benefits from Bitcoin volatilities and its market inefficiencies (Bouri et al. 2018). It is important to highlight that this inefficiency is getting weaker over time since liquidity seems to have a positive effect on the informational efficiency of Bitcoin prices (S Kumar and Ajaz 2019).

(C) The Author(s). 2020 Open Access This article is distributed under the terms of the Creative Commons Attribution 4.0 International License (http://creativecommons.org/licenses/by/4.0/), which permits unrestricted use, distribution, and reproduction in any medium, provided you give appropriate credit to the original author(s) and the source, provide a link to the Creative Commons license, and indicate if changes were made. 
This study seeks to advance knowledge of how Bitcoin prices are set by the market, to identify the relevant variables affecting the Bitcoin market, and to provide a technical reference for the investors that believes in its appreciation over time and invests in this asset. The findings are also relevant for policymakers and monetary authorities in order to understand why people are seeing increasingly their interests to trade or hold Bitcoin. Understanding these interests is fundamental to create alternatives to avoid governments having their currencies depreciated against Bitcoin.

Some studies point to three major variables that influence the Bitcoin price: macroeconomic/financial, such as dollar quotation and stock exchange index; attractiveness, such as increased interest in the asset evidenced by its increasing appreciation over the years; and the dynamics between demand and supply.

The initial hypothesis of the research is that attractiveness factors influence the Bitcoin price at both global and local levels, updating previous studies of attractiveness pricing. These combined attractiveness factors define the interest of the world's population in the asset, as measured by the number of Google searches for the terms bitcoin and bitcoin crash between December 2012 and February 2018.

This study adds to the analysis the crisis variable through a measurement of the number of Google searches using the term crisis. It seeks to verify if, in troubled periods of crisis with repercussions at the global level, Bitcoin tends to be more attractive as an alternative investment, as evidenced by an increase in its price.

The vector error correction model is the methodology chosen to test the hypothesis that the number of Google searches using the terms bitcoin and bitcoin crash affects the Bitcoin price and that, in times of increasing searches for news about crisis, there is an accompanying increase in the value of the digital currency. It is anticipated that the hypotheses and a feedback effect between endogenous variables will be confirmed.

\section{Functions of money}

Nakamoto (2008) described Bitcoin as an electronic currency embedded in a peer-topeer system and capable of being transferred directly from one participant to another without the intermediation of a financial institution. A process called proof of work helps to assure that duplicate transfer expenses are avoided. Through this process, the Bitcoin network confirms each transfer as legitimate and unique by analyzing the digital signature and recording the chronological order in which the transaction took place.

The transactions recorded and confirmed are inserted into a block that becomes part of the blockchain, through a process known as mining. This chain of blocks, which contains all transaction history, is constantly sent to network participants to inform them of the new operations. In this sense, Nakamoto (2008) compared the digital currency to a stream of digital signatures.

This entire technological and cryptographic framework already makes Bitcoin different from sovereign currencies, primarily because of its ability to be cited as a representation of digital value and its virtual decentralization. In this sense, there is no consensus among scholars about using of the term currency when referring to Bitcoin. Some relevant aspects of Bitcoin differ from traditional fiduciary currencies that will be analyzed. 
Initially, it is important to review some of a currency's economic functions: as a medium of exchange, enabling the purchase (or sale) of products and services upon delivery (receipt) of the currency; as a unit of account, from which goods and services are priced; and as a store of value that ensures the maintenance of purchasing power and wealth over time, and sometimes allowing interest income through investment in financial assets. The question is whether Bitcoin has all these properties to be termed as currency. Yermack (2015) and Ciaian et al. (2016a) differ in this regard.

Virtual money use has increased as a medium of exchange in the e-commerce environment where major brands such as Microsoft and Subway have offered it as a payment method in online purchases. The speed and low cost of transferring Bitcoin, the anonymity of the transference, and the transparency of transactions recorded in the blockchain are positive aspects that promote adoption of Bitcoin as cash.

However, legal issues may compromise Bitcoin's role as a medium of exchange since sovereign governments has authority to prohibit its adoption by their populations and emphasize negative aspects such as cyberattacks and virtual crimes-all characteristics that are cited by an analysis by Ciaian et al. (2016a). While investigating fraudulent activities at the MtGox brokerage firm aimed at leveraging the Bitcoin price, Gandal et al. (2018) highlighted threats to the Bitcoin network, such as Ponzi schemes, theft of Bitcoin brain wallets, and malware. Also, cryptocurrencies could be illegally used to facilitate Trade-based Money Laundering (TBML) schemes and it can be justified by the easy way the digital coins are transferred. Chao et al. (2019) say that TBML is seriously concerned by emerging markets and developing economies in a way that regulations and methods to monitor and fight against it have been created.

The lack of regulation is also an unfavorable criterion, since it eliminates judicial settlements of disputes and makes it difficult to obtain reimbursement from operations prejudiced against cryptocoins. In November 2017, the Central Bank of Brazil - Bacen (2017) said that does not regulate or supervise virtual currencies even though it monitors related discussions in international forums. In addition, the bank emphasized the imponderable risks of this type of investment to the market, including the loss of all invested capital.

Concerning the unit of account function, Ciaian et al. (2016a) highlighted the high volatility of Bitcoin pricing as costly from the point of view of the virtual re-mark of goods and services prices denominated in Bitcoin monetary units. This function is the main differentiating factor between Bitcoin and sovereign currencies. Another striking difference concerns to divisibility since the coin can be denominated beyond two decimal places (the smallest fraction of Bitcoin is called satoshi and corresponds to one hundredth of millionth of Bitcoin). Yermack (2015) stated that the market can be disconcerted about the use of multiple decimal places, hindering price comparisons by the consumer.

Regarding the store of value function, Ciaian et al. (2016a) also stated that Bitcoin has two important advantages over other currencies: the fact that the offer is predetermined by the platform and is protected by cybersecurity since all registrations made in the blockchain are unchangeable. Volatility and cyberattacks are negative factors in this regard.

In addition, investment in virtual currencies can generate interest income, including through available platforms, such as BitPass, that offer interest payments to customers who leave their bitcoins stored for a certain period of time. 


\section{A brief literature review}

Bitcoin pricing has been the subject of research by scholars who seek to infer the variables that affect Bitcoin value. In the literature, basically, three groups of these variables are found: macroeconomic and financial; attractiveness; and the dynamics between demand and supply. There are studies that focus on just one of these groups and others that seek to conduct a more holistic analysis by covering all of them.

Some authors have verified in their research that macro-financial variables do not have a statistically significant influence on Bitcoin pricing in the long term (Bouri et al. 2017; Chao et al. 2019; Ciaian et al. 2016a; Polasik et al. 2015). The price of gold, much compared to Bitcoin, also does not seem to be related to Bitcoin pricing (Bouoiyour and Selmi 2015; Kristoufek 2015). However, in the short term, economic factors seem to have a significant impact, as in the U.S. dollar quotation (Dyhrberg 2016; Zhu et al. 2017) and in the Chinese market represented by the Shanghai index (Bouoiyour and Selmi 2015; Kristoufek 2015).

It is interesting to note that most published studies give important prominence in their analyses to attractiveness factors, such as the variable number of searches over time using the term bitcoin in Google Web Search. In the early years of Bitcoin consolidation, tests based on vector autoregressive and vector error correction methodologies indicated that the amount of searches on Google and Wikipedia had a strong temporal association with the price curve, i.e., that public interest in increasing knowledge about the asset's operation was followed by the increase in its price (Buchholz et al. 2012; Kristoufek 2013; Kristoufek 2015). However, with the subsequent consolidation of the currency and the population's greater knowledge concerning Bitcoin's operation, the attractiveness factor has increasingly failed to have the same relevance as before (Ciaian et al. 2016a; Hayes 2017) even though attractiveness is still a valuable variable for pricing analysis.

The final group concerns the dynamics between demand and supply. The equilibrium point of the supply and demand curve determines the Bitcoin price in a brokerage firm. However, what is peculiar about this digital currency is that the supply curve is known and pre-determined since there is a definitive limit on the quantity of virtual money offered in the market. Therefore, variations in the factors that determine and directly impact the demand curve enable the high volatility of this currency over time. In this sense, research seeks to use the variables that directly influence demand to predict currency pricing.

\section{Macroeconomic drivers}

Zhu et al. (2017) is one of the most recent studies about the impact of macroeconomicfinancial factors on Bitcoin pricing. The author used some of the variables that affect gold pricing to identify those that have the same effect on Bitcoin pricing. The study defined Bitcoin as an investment asset rather than as a currency, because of its sensitivity to variations in macroeconomic indices. The study also noted that there was evidence of Granger causality in relation to gold price (GP) and dollar index (USDI) factors as applied to the dependent variable Bitcoin price.

According to Zhu et al. (2017), the influence of the USDI was negative, possibly because a valuation of the U.S. dollar currency against other currencies is also applicable 
to the virtual currency Bitcoin. Therefore, it was inferred that at the moment of U.S. dollar appreciation, there would be a devaluation of the Bitcoin price denominated in dollars. In the second half of 2014, for example, there was a continuous increase in the USDI caused by the resumption of the U.S. economy and, at the same time, there was a significant drop in the Bitcoin price.

Based on this behavior, Dyhrberg (2016) said that bitcoin could be used as a hedging product for the dollar exposure in the short term and as an additional instrument for market analysts to protect against specific risks. It should be noted that the dollar quotation against other currencies was negatively correlated with the Bitcoin price, not only in the short term but also in the long run, according to Van Wijk (2013) and Zhu et al. (2017).

Zhu et al. (2017) also stated that changes in the federal funds rate (FFR), established by the Federal Reserve System, had a negative impact on the Bitcoin price in the short term. The study cited two main reasons for this conclusion: an increase in the dollar's exchange rate on the foreign exchange market due to migration of financial capital to the U.S.; and a reduction in the attractiveness of speculative investments that entail high risk because of an increase in the U.S. fixed income market.

The Dow Jones index, according to Van Wijk (2013), seemed to be positively correlated in the short and long term with the Bitcoin price. The study suggested an improvement in the performance of the U.S. economy could generate positive effects on Bitcoin pricing. Bouoiyour and Selmi (2015) saw the Shanghai index as a positive and short-term influence because of their perception that the Shanghai market was one of the big players in transactions with the virtual currency. Kristoufek (2015) also highlighted the impact of the Chinese economy on the Bitcoin price. In contrast, Dyhrberg (2016) said Bitcoin might be a possible hedging instrument against FTSE index variations, having no correlation with the 100 largest listed companies on the London Stock Exchange.

There are authors who report that they find no consistent evidence regarding the causal relationship between macroeconomic variables and the Bitcoin price. When including demand and attractiveness variables in their model, Ciaian et al. (2016b) concluded that there was no significant statistical relevance of macroeconomic factors such as the Dow Jones index and oil prices and suggested speculation was the primary driver of price. Polasik et al. (2015) concluded that the correlation between Bitcoin returns and the fluctuations of sovereign currencies was weak and statistically insignificant. AlKhazali et al. (2018) argued via a GARCH model that Bitcoin is weakly related to macro-developments due to low predictability for Bitcoin return and volatility after macroeconomic news surprises. According to Al-Khazali et al., the cryptocurrency acts more like a risky asset than a safe haven instrument.

\section{Attractiveness drivers}

Bitcoin emerged at a time of massive expansion of the Internet, search engines, and social networks. Because it is a virtually mined coin and with peculiar characteristics, there is a certain unfamiliarity with its modus operandi, even to those who use in their day-to-day interactions with the Internet. Bitcoin it is not simple to understand since this is a new technology based on encryption and codifications that are more technically familiar to information technology professionals. 
Searches on electronic media for information about what Bitcoin is and how it works may be a variable that explains demand increases for the coin and, consequently, its price. Some authors sought to estimate a relationship between the search history of the term Bitcoin on platforms such as Google (Kristoufek 2013; Buchholz et al. 2012; Bouoiyour and Selmi et al. 2015; Polasik et al. 2015; Nasir et al. 2019), Wikipedia (Kristoufek 2013), Twitter (Davies 2014) and online forums (Kim et al. 2017).

Polasik et al. (2015) described popularity as a strong factor for Bitcoin price returns. The authors further stated that a $1 \%$ increase in the number of articles mentioning the term bitcoin generated an approximate return of 31 to 36 basis points in its price. This percentage is even higher when an analysis is based on Google's database, where the return can be from 53 to 62 basis points. Buchholz et al. (2012) concluded that Google searches had a causal effect on Bitcoin transactions; however, the opposite did not seem to be applicable. Nasir et al. (2019), by using copulas and a nonparametric approach, confirmed that Google searches have a direct relationship with Bitcoin performance, particularly in the short run: the more often the investors look for information about the cryptocurrency, the higher the returns and trading volume that follow.

Although the attractiveness variable, represented by quantification of searches and use of the term bitcoin in certain relevant sites, was of great value for predicting the price of the currency for some authors, it is limited by the horizon of long-term analysis. Ciaian et al. (2016b), when analyzing a database with a higher data history between 2009 and 2015, indicated that online searches were better predictors of punctual returns in the early years of bitcoin. With the consolidation of the currency, we can see a reduction in the relevance of this prediction. Hayes (2017) believed that searches for the term bitcoin would lessen with the spread of knowledge about the currency and make the variable unsatisfactory for inclusion in predictive models. Bouoiyour and Selmi's analysis also did not find evidence of the impact of Google searches on price in the long run.

\section{Demand versus supply}

Ciaian (2016a) demonstrated that the increase in the number of available bitcoins (inventory) was related to a decrease in its price, while the increase in the number of addresses (virtual portfolios) accompanied an increase in price. Civitarese (2018) analyzed the value of Bitcoin based on the growth of network users using the Metcalfe law, and verified the existence of a consistent relationship between the number of portfolios and the short-term Bitcoin price, although the study rejected the hypothesis of cointegration between the real price and prices calculated by law. Considering that the amount of currency offered by the Bitcoin platform is finite and known, Buchholz et al. (2012) stated that fluctuations in the Bitcoin price occurred mostly because of shocks in the demand curve. In addition to the factors highlighted above, there are others that measure the size of the Bitcoin market and cause a direct shock to the curve. Such examples include the volume variables of daily transactions and transfers by network users.

The volume variable, according to Bouoiyour and Selmi (2015), impacts Bitcoin pricing in the short term. Balcilar et al. (2017) emphasized that the variable can predict returns, except in up- or down-market periods. Therefore, under normal market 
conditions, investors have transacted volume as a prediction tool; in contrast, during stress scenarios, an association between the variable and price returns is not identified.

The increasing realization of Bitcoin transactions tends to stimulate its adoption by other economic agents, boosting the demand for bitcoins. Ciaian et al. (2016b) noted that the size of the bitcoin economy's impact on demand tends to grow over time. The expectation is that the more frequent the use of money, the greater the demand and, consequently, the higher the price for bitcoins (Kristoufek 2015). Polasik et al. (2015) cited e-commerce as a major driver of payment systems that do not involve banking institutions and, in this sense, payment service providers aid in the development and adoption of virtual currencies.

\section{Methods}

The perception that search for Bitcoin acquisition is related to the population's growing interest in the virtual currency can be verified using short- and long-term analysis based on i) price, ii) number of searches for the word bitcoin in Google and (iii) number of searches for the word bitcoin crash in Google. The methodology chosen to evaluate this hypothesis is the vector error correction model (VECM), derived from vector autoregressive (VAR) model, to be detailed below.

The word bitcoin was chosen due to two reasons: i. btc is one of the top five most frequently used keywords in the literature about blockchain (Xu et al. 2019) and ii. cryptocurrency prices are influenced by Bitcoin price movements (S Kumar and Ajaz 2019).

\section{Vector autoregressive model}

VAR is an autoregressive model composed of p-lags and a vector with $\mathrm{n}$ endogenous variables. The methodology differs from univariate models by analyzing the trajectory caused by a structural shock on endogenous variables.

The Eq. 1 expresses the reduced form of VAR. $X_{t}$ is a vector $n \times 1$ and establishes the selected endogenous variables. $\Pi_{0}$ is a vector $\mathrm{n} \times 1$ which contains the constants. $\Pi_{i}$ is relative to the matrices of coefficients $\mathrm{n} \times \mathrm{n}$. The vector $\varepsilon_{t}$ refers to independent, random and uncorrelated disturbances $\left(\varepsilon_{t \sim \text { i.i.d. }}\left(0 ; \mathrm{I}_{\mathrm{n}}\right)\right)$.

$$
X_{t}=\Pi_{0}+\sum_{i=1}^{p} \Pi_{i} X_{t-i}+\varepsilon_{t}
$$

In VAR analysis, therefore, $\mathrm{n}$ variables are established to compose the model, which will contemplate $\mathrm{n}$ equations so that each variable is dependent on one of the equations and independent on the others. Each equation has as independent variable lags of the dependent variable itself and lags of the other variables, plus an error term. The objective of this model is to understand how past data influences the values of the dependent variable in the present. It should be noted that the dependent variables are endogenous.

The generalization of VAR model, order $\mathrm{p}$, with the addition of exogenous variables is given by Eq. 2. Being $\phi$ the coefficient vector $\mathrm{n} x \mathrm{~g}$ and $\mathrm{D}$ is the matrix containing exogenous variables. 


$$
X_{t}=\Pi_{0}+\sum_{i=1}^{p} \Pi_{i} X_{t-1}+\Phi D_{t}+\varepsilon_{t}
$$

The ordinary least squares (OLS) method can be used in the VAR to consistently estimate the coefficients. The optimal choice of the lags to be added to the regression mitigates the existence of the serial correlation in the residuals.

\section{Vector error correction model}

The VEC model (VECM) can be obtained from a special configuration of VAR parameters. When the variables established in VAR are cointegrated, it is recommended to adopt VECM. The difference with VAR model lies in the inclusion of an error correction term that seeks to measure how the system reacts to long-term equilibrium deviations caused by shock in the variables.

The advantage of the model is the consideration of the economic behavior of the studied variables, because it allows the study of the long- and short-term dynamics of the variables and also because it seeks not to omit relationships among the variables that could be suppressed in the differentiation process.

Based on Engle and Granger (1987), the cointegration is characteristic of a series vector $X_{t}$, with the same order of integration $\mathrm{d}$, whose linear combination results in a process with integration order $\mathrm{d}$ minus $\mathrm{b}$, according to Eq. 3 .

$$
\exists \beta \neq 0 \text { and } \mathrm{Z}_{\mathrm{t}}:=\beta^{\prime} X_{t} \sim \mathrm{I}(\mathrm{d}-\mathrm{b}) \text {, with } \mathrm{b}>0
$$

Based on the case of series with a unit root, if each element of a vector of time series $X_{t}$, stationary only after the first differentiation, generates by linear combination $\beta X_{t} a$ stationary process with finite variance, they are said to be cointegrated. In practice, two non-stationary series with a stochastic tendency and with common displacements over time are said to be cointegrated.

Considering that most of the economic series are integrated of order 1, the stationarity test is applied to error $\mathrm{Z}$, aiming to confirm the hypothesis of cointegration between the variables. There are basically two main tests that can be used in this verification process: the Engle-Granger cointegration test (1987) and the Johansen test (1988).

Engle and Granger sought to check the cointegration between the variables by obtaining an equation that represents the long-term relationship between them, using a least squares methodology. Once the relationship has been established, the residues are extracted and the Dickey-Fuller (ADF) test is applied to verify their stationarity. Once stationarity is confirmed, the VEC model can be used.

In its turn, the Johansen (1988) uses VAR model and the matrix of its coefficients to determine its rank and, in this way, estimates the cointegration vectors.

According to Pfaff (2006), the VEC can be specified by Eqs. 4a, 4b and 4c, which are called transitory.

$$
\begin{aligned}
& \Delta \mathrm{X}_{\mathrm{t}}=\Pi \mathrm{X}_{\mathrm{t}-1}+\sum_{i=1}^{p-1}\left(\Gamma_{i} \Delta \mathrm{X}_{t-i}\right)+\Phi D_{t}+\varepsilon_{t}, \\
& \Pi=-\mathrm{I}+\sum_{i}^{p}\left(\Pi_{i}\right)=\alpha \beta^{\prime}
\end{aligned}
$$




$$
\Gamma_{i}=-\sum_{j=1+i}^{p}\left(\Pi_{j}\right), i=1,2, \ldots, p-1
$$

The short-term factors that explain deviation of endogenous variables are given by

the term $\sum_{i=1}^{p-1}\left(\Gamma_{i} \Delta \mathrm{X}_{t-i}\right)$. The long-term relationship is given by $\Pi \mathrm{X}_{\mathrm{t}-1}$, with $p$ being the number of lags in the model. The term $\Pi$ can be decomposed into $\alpha$, the adjustment matrix, and $\beta$, the cointegration matrix.

In the present research, each variable within the term $\Delta \mathrm{X}_{t-i}$ will be represented by $\Delta$ variable $_{t-i}$.

\section{Granger causality test}

According to Pfaff (2006), in using Granger causality test, the endogenous variables of the model are separated into two vectors $X_{1}$ and $X_{2}$, of dimensions $\left(k_{1} \times 1\right)$ and $\left(k_{2} \times\right.$ 1 ), being the sum of $k_{1}$ and $k_{2}$ equal to the number of endogenous variables. Detailing the matrices, the VAR is established in Eq. 5. The hypothesis that can be tested is whether the $\mathrm{X}_{1}$ Granger-causes $\mathrm{X}_{2}$. For this, it is possible to test through $\mathrm{F}$ test if $\Pi_{21, i}$ is nonzero for $i=1,2, \ldots, p$.

$$
\left[\begin{array}{l}
X_{1 t} \\
X_{2 t}
\end{array}\right]=\sum_{i=1}^{p}\left[\begin{array}{cc}
\Pi_{11, i} & \Pi_{12, i} \\
\Pi_{21, i} & \Pi_{22, i}
\end{array}\right]\left[\begin{array}{c}
X_{1, t-1} \\
X_{2, t-1}
\end{array}\right]+\varepsilon_{t}
$$

\section{Database}

The selected database to be considered by the model was found in three electronic data sources: Google Trends (2018), Bitcoincharts (2018) and Bitcoin.com (2018). The period studied is the weeks between December 17, 2012 and February 12, 2018. The database starts in December 2012 due to a technical limitation of Google Trends; until that date, the tool produced weekly observations, while the extended period generates monthly observations.

Bitcoin.com is a platform that aims to help Bitcoin stakeholders by offering news, brokerage, and quantitative analysis tools. In the charts section, it is possible to obtain the Bitcoin price history based on the Composite Price Index (BCX), a price index that measures the value of Bitcoin in U.S. dollars and is formed by the quadratic average of four price indices that represent the average prices among the world's largest Bitcoin brokerage firms. Once the daily BCX curve was obtained, the average daily price for weekly data aggregation was computed. The average daily price for 1 week, therefore, represents each observation of the price variable in the overall analysis of the survey.

The Bitcoincharts platform is also a quantitative analysis tool that provides the Bitcoin price. However, it details the data by date, by sovereign currency, by brokerage and by volume; therefore, it is possible to have greater detail of the behavior of the price in different regions and even to analyze the spread between different countries. For the currency analysis, prices were selected in twelve sovereign currencies, specifically those that have presented data for the period required and with higher volumes traded at the brokerage firms. Therefore, the local price is denominated in the respective sovereign currency, based on the negotiations between users of these currencies. These prices will be the price variable of the analysis by currency. 
Google Trends is a tool provided by Google that provides information about the number of searches on the platform for a particular word or term, and providing the ability to specify the analysis for a given period and country. The numbers obtained are normalized in the range of 0 to 100 , so that 100 represents the highest popularity peak of a term in a given region over a given period. The terms searched in the tool were bitcoin and bitcoin crash covering the whole world and all categories. The result of these two surveys generated two curves with weekly values that will represent the btc and crash variables. Peaks in Google Trends searches for the term bitcoin crash as shown in Graph 1 is a graphical representation of negative news events that have had an intense and negative impact on Bitcoin's price. Details of these events will attempt to demonstrate that bitcoin pricing seems to be highly sensitive to such sudden events.

The search in the Google Trends (category equal to news) for the term crisis was also added to the analysis. The curve obtained is described in Graph 2, which is about the impact of crises on Bitcoin pricing. Based on the weekly return calculation of this curve, we selected the five largest positive returns for determining the crisis dummy variable. The purpose is to analyze whether, during the five biggest positive changes caused by the increase in the number of searches for crisis news, the Bitcoin price also increased. If the database week corresponded to one of those times of greatest variation, the dummy crisis for that week was equal to 1, otherwise the value was zero.

The resulting variables are price, btc, crash, and crisis. In all of them the transformation of the natural logarithm was applied to minimize problems of heteroscedasticity and to make the model estimators less sensitive to unequal estimates (Wooldridge 2006). In order to denote this change, the prefix $\ln$ will be appended to the variable names (resulting in lnprice, lnbtc and lncrash).

According to Graph 3, a long-term relationship between lnprice and lnbtc curves was observed, with the aspect of cointegration between them. The choice to use the VEC model is due to the need to understand if there is an influence of the attractiveness

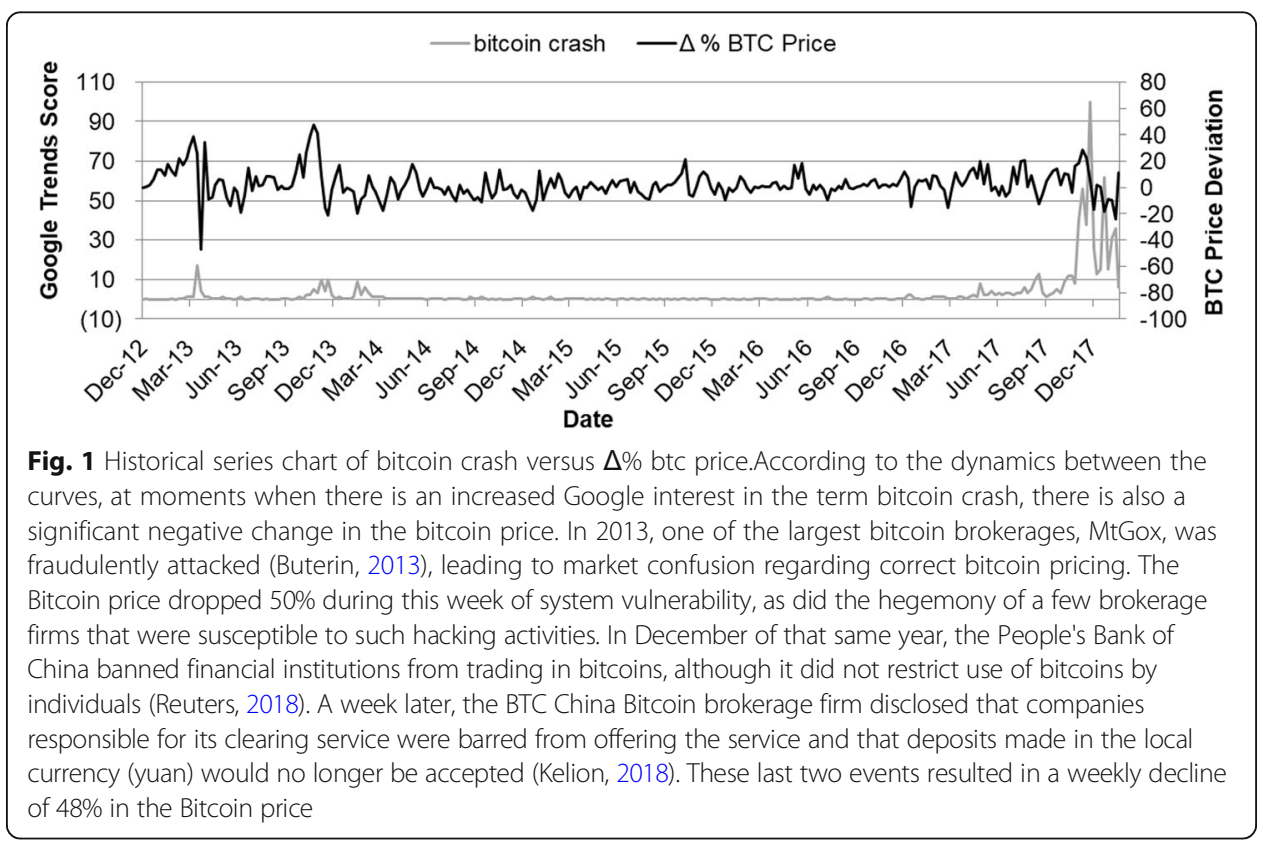




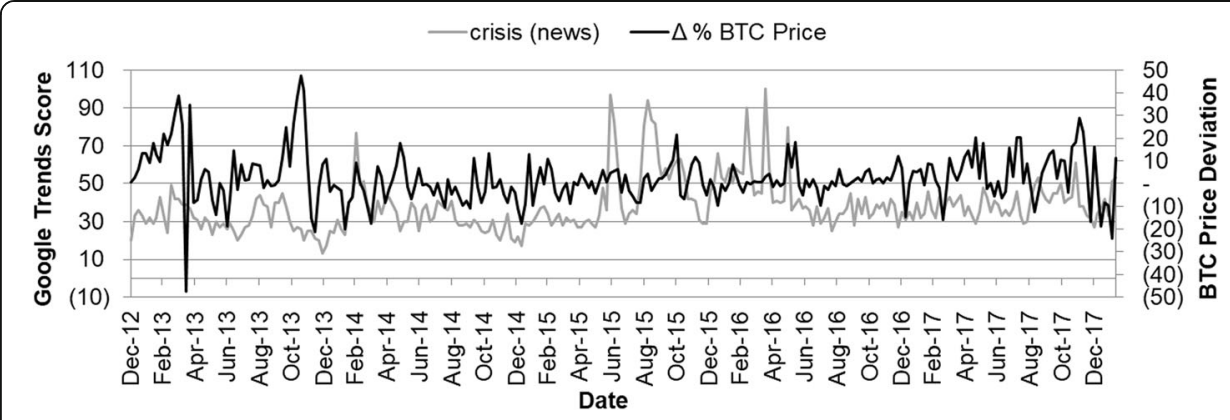

Fig. 2 Historical series of crisis versus $\Delta \%$ btc price. The biggest change in the number of online news stories about an economic crisis-a $99 \%$ increase from one week to the next-occurred during the week of June 28, 2015. According to G1 (2018), Greece had failed to pay part of its indebtedness to the International Monetary Fund (IMF). In addition, the country declared a bank holiday and limited electronic withdrawals to no more than $€ 60$ a day. A rather pessimistic scenario developed with the increasing probability that Greece would adopt capital controls and possibly leave the European Union. The country's exit would result in a devaluation of the euro, probable default on Greek debt, an increase in investor mistrust regarding the economic future of the emerging countries. Concurrent with the Greek crisis and subsequent to the peak news date, Bitcoin price increased for three consecutive weeks, a 17\% appreciation. Brokers around the world reported a sudden upsurge in computer operations originating in Greece, with China's LakeBTC experiencing a $40 \%$ increase in Greek participation on its platform (Pagliery, 2018). Such an increase was not limited to Greece. The brokerage firm, BTC.sx, reported an increase in the number of operations coming from the Eurozone (Kwan, 2018). According to Grendan O'Connor, CEO of the electronic platform Genesis Trading, the Greek crisis appeared to be the only relevant factor in the bitcoin price increase. He added that the firm's trading desk raises the price of virtual currencies in cases of macroeconomic events that are detrimental to the main sovereign currencies (Rosenfeld, 2018).

factor in the price and if the price also explains the factors of attractiveness in the short and long term. In this way, the model allows the construction of equations in which the price is dependent variable while, in the other equation, it is independent, plus price information lagged. The insertion of the error correction term allows understanding the long term dynamics, which would not be possible in a process of differentiation of the variables.

In order to run VECM, a level data series is used without any stationarity transformation, and the two main stages are performed in advance. The first concerns the selection of the number of lags that optimize the analysis; Bueno (2015) emphasizes that the choice must contemplate the optimal lag considering all variables under analysis to obtain white noises in all of them. The second stage consists of the application of the Johansen cointegration test (1988), by the trace and eigenvalue statistics, through the

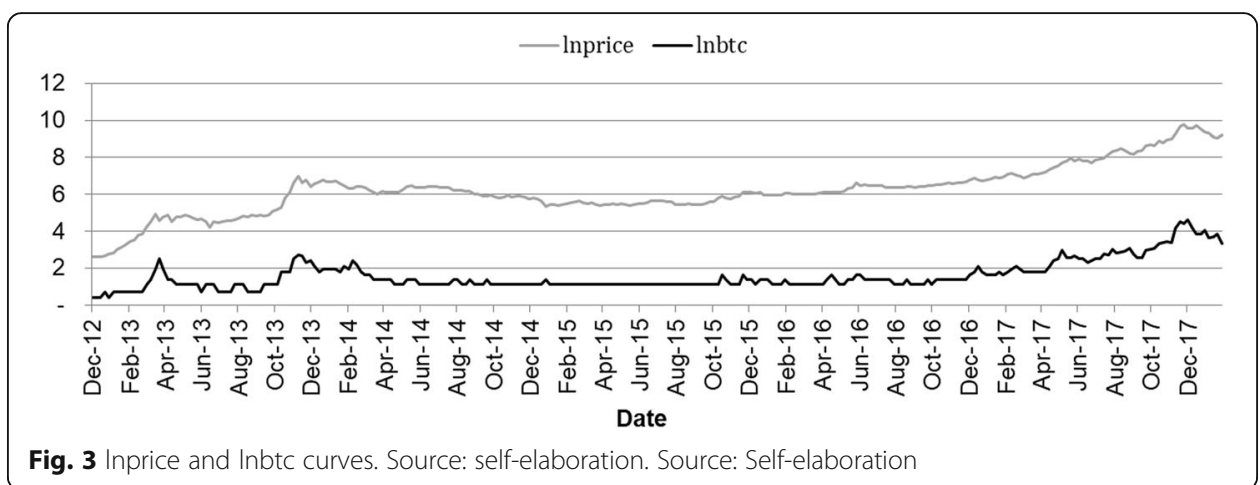


function ca.jo of the Rstudio urca package. The cointegration rank is determined at this stage.

The cajorls function for extracting VEC model regressions is then applied based on the determination of amount of error correction terms.

Applying the Eq. 4a to the database, the previous VEC will be given by Eq. 6 .

$$
\left[\begin{array}{c}
\Delta \operatorname{lnprice}_{t} \\
\Delta \operatorname{lncrash}_{t} \\
\Delta \operatorname{lnbtc}_{t}
\end{array}\right]=\alpha \beta\left[\begin{array}{c}
\operatorname{lnprice}_{t-1} \\
\operatorname{lncrash}_{t-1} \\
\operatorname{lnbtc}_{t-1}
\end{array}\right]+\sum_{i=1}^{p-1} \Gamma_{i}\left[\begin{array}{c}
\Delta \operatorname{lnprice}_{t-i} \\
\Delta \operatorname{lncrash}_{t-i} \\
\Delta \operatorname{lnbtc}_{t-i}
\end{array}\right]+\Phi \text { crisis }_{t}+\text { constant }+\varepsilon_{t}
$$

\section{Results}

\section{Global analysis}

The ADF test describes lnprice, lncrash and lnbtc variables as being integrated of order 1, I (1). After differentiation, they become stationary, according to Table 1.

The lag order selection criteria results in two lags, according to Akaike Information (1969), Hannan-Quinn (1979), Schwarz (1978) and Final Prediction Error (1969). Based on this, two lags were selected for parameterization of the Johansen cointegration test (1988), as shown in Table 2.

The application of the Johansen cointegration test shows that the price curve and the lnbtc and lncrash variables are cointegrated, and the test rejects the null hypothesis of non-existence of a cointegration vector. Also, it does not reject the null hypothesis of existence of two cointegration vectors, according to Table 3. From this result, the VECM proves to be more adequate than the VAR, with the insertion of the error correction terms to perform the long-term adjustment in the system.

After obtaining the number of lags (p) and cointegration vectors, we complete Eq. 6 and we have the final Eq. 7.

$$
\left[\begin{array}{c}
\Delta \text { lnprice }_{t} \\
\Delta \text { lncrash }_{t} \\
\Delta \text { lnbtc }_{t}
\end{array}\right]=\alpha_{1} \beta_{1}^{\prime}\left[\begin{array}{c}
\text { lnprice }_{t-1} \\
\text { lncrash }_{t-1} \\
\text { lnbtc }_{t-1}
\end{array}\right]+\alpha_{2} \beta_{2}^{\prime}\left[\begin{array}{c}
\text { lnprice }_{t-1} \\
\text { lncrash }_{t-1} \\
\text { lnbtc }_{t-1}
\end{array}\right]+\Gamma_{1}\left[\begin{array}{c}
\Delta \text { lnbtc }_{t-1} \\
\Delta \text { lncrash }_{t-1} \\
\Delta \text { lnbtc }_{t-1}
\end{array}\right]+\Phi \text { crisis }_{t}+\text { constant }+\varepsilon_{t}
$$

Table 4 presents the parameters of the cointegration matrix $\beta_{1}$ and $\beta_{2}$ of the error correction term. In Table 5, the adjustment coefficients of the error correction term are presented, $\alpha_{1}$ and $\alpha_{2}$.

It should be noted that the coefficient of lnprice $_{t-1}$ is positive in $\beta_{1}$, so that a rise of Inprice in $\mathrm{t}-1$, not accompanied by a proportional increase of the variable $\operatorname{lnbtc}_{\mathrm{t}-1}$,

Table 1 Augmented Dickey-Fuller test applied to variable of the analysis

\begin{tabular}{lcc}
\hline Variable & $T$ test & $P$-value \\
\hline Inprice & -2.29 & 0.45 \\
Incrash & -1.70 & 0.70 \\
Inbtc & -1.61 & 0.74 \\
crisis & -5.48 & $<0.01$ \\
$\Delta$ Inprice & -5.11 & $<0.01$ \\
$\Delta$ Incrash & -7.86 & $<0.01$ \\
$\Delta$ Inbtc & -6.34 & $<0.01$ \\
\hline
\end{tabular}


Table 2 Lag (p) order selection criteria

\begin{tabular}{llllll}
\hline Criteria & 1 & 2 & 3 & 4 & 5 \\
\hline AIC & -10.270930 & -10.505740 & -10.476150 & -10.474250 & -10.426500 \\
HQ & -10.205800 & -10.391760 & -10.313320 & -10.262580 & -10.165980 \\
SC & -10.108830 & -10.222060 & -10.070900 & -9.947423 & -9.778095 \\
FPE & 0.000035 & 0.000027 & 0.000028 & 0.000028 & 0.000030 \\
\hline
\end{tabular}

which neutralizes this increase, represents a deceleration in the $\Delta$ lnprice in $\mathrm{t}$, considering the fact $\alpha_{1}$ is negative. On the other hand, the coefficient of $\operatorname{lnbtc}_{t-1}$ is negative in $\beta_{1}$, which means that an increase of $\operatorname{lnbtc}_{t-1}$, not accompanied by lnprice $e_{t-1}$, generates a pressure so that in the following period the variation of lnprice also increase.

The coefficient of adjustment $\alpha_{2}$, applied to the cointegration matrix $\beta_{2}$ is also negative in the equation $\Delta$ Inpreço $_{t}$. By analyzing the coefficients of $\beta_{2}$, it is inferred that a sudden increase of $\operatorname{lnbtc}_{t-1}$, results in a negative error which, when multiplied by $\alpha_{2}$, leads to an increase of $\Delta$ lnprice. In contrast, a sudden increase of $\operatorname{lncrash}_{\mathrm{t}-1}$ generates a positive error which, when multiplied by $\alpha_{2}$, generates a decrease of $\Delta$ lnprice.

As described, $\alpha_{1}$, the adjustment coefficient of the error correction term, is consistent at significance level of $5 \%$ and is negative in the price equation $\Delta$ lnprice $_{t}$, inferring that a deviation from the long-term dynamics caused by shock of the factors under analysis is minimized with the correction proposed by $\alpha_{1}$ for the following period, as Engle and Granger point out (1987). The sum of the alphas allows to infer that $\alpha_{1}$ e $\alpha_{2}$ contribute proportionally with $59 \%$ and $41 \%$, respectively, for long-term dynamics.

The analysis of VECM results, summarized in Table 5, shows that the coefficient of the independent variable $\Delta \operatorname{lnbtc}_{\mathrm{t}-1}$, in the regression $\Delta \operatorname{lnpreço}_{\mathrm{t}}$, is positive, equal to 0.07 and significant only to level of $10 \%$. In this sense, it is inferred that a $1 \%$ increase in Google searches for the term bitcoin may be accompanied in the following period by a weekly increase of $0.07 \%$ of the current price of the digital currency.

When analyzing the regression of the dependent term $\Delta \operatorname{lnbtc}_{\mathrm{t}}$, the independent variable $\Delta$ lnpreço $\mathrm{O}_{\mathrm{t}-1}$ is significant at the $5 \%$ level. It is inferred, therefore, that a $1 \%$ increase in the Bitcoin price is followed in the following period by a weekly increase of around $0.92 \%$ of searches for Bitcoin. With these results, it is possible to establish a bidirectional dynamic between lnbtc and lnprice. It is suggestive that the intensification of the interest of the population in Bitcoin influences positively the value of the currency and the reverse also seems to be coherent, that is, the increase of the price intensifies the number of searches.

To confirm the feedback effect, we performed the Granger causality test. The vector $\mathrm{X}_{1}$ is declared to contain the variables $\Delta$ lnbtc and $\Delta$ lncrash. $X_{2}$ is composed of $\Delta$ lnprice. At the $5 \%$ confidence level, the feedback effect is confirmed and states that

Table 3 Johansen Cointegration test with maximum eigenvalue form

\begin{tabular}{|c|c|c|c|c|}
\hline \multirow{2}{*}{$\begin{array}{l}\text { Cointegration } \\
\text { rank }\end{array}$} & \multirow[t]{2}{*}{ Test } & \multicolumn{3}{|c|}{ Critical values } \\
\hline & & $10 \%$ & $5 \%$ & $1 \%$ \\
\hline$r=0$ & $79.92^{* * *}$ & 18.90 & 21.07 & 25.75 \\
\hline$r<=1$ & $27.96^{* * *}$ & 12.91 & 14.90 & 19.19 \\
\hline$r<=2$ & 1.29 & 6.50 & 8.18 & 11.65 \\
\hline
\end{tabular}


Table 4 Coefficients of the cointegration matrix $(\beta)$ from error correction term

\begin{tabular}{|c|c|c|c|c|c|c|}
\hline \multirow[t]{2}{*}{ Variable } & \multicolumn{3}{|l|}{$\beta 1$} & \multicolumn{3}{|l|}{$\beta 2$} \\
\hline & Coef. & $\sigma$ & t-value & Coef. & $\sigma$ & t-value \\
\hline Inprice $_{t-1}$ & 1.00 & - & - & - & - & - \\
\hline $\operatorname{lnbt} c_{\mathrm{t}-1}$ & $-1.74^{* * *}$ & 0.22 & -7.89 & $-0.88^{* * *}$ & 0.08 & -10.44 \\
\hline Incrash $_{\mathrm{t}-1}$ & - & - & - & 1.00 & - & - \\
\hline
\end{tabular}

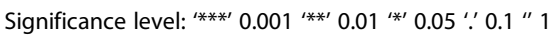

$\Delta$ lnprice Granger-causes $\Delta \operatorname{lnbtc}$ and $\Delta$ lncrash. The converse is also true, that is, $\Delta \operatorname{lnbtc}$ and $\Delta$ lncrash Granger-cause $\Delta$ lnprice, as presented in Table 6.

The independent variable $\Delta \operatorname{lncrash}_{t-1}$, which identifies the moments in which there was some negative event for the virtual currency community, resulted in the equation $\Delta$ Inprice $_{t}$, a negative and significant coefficient, in both specifications. This is an intuitive result since negative events tend to be accompanied by an increase in market mistrust and, consequently, a fall in price. This variable is fundamental, while allowing the model to identify the moments in which there is an intense fall of the price and better adjusting the curve of the model to the valleys. It is estimated that a positive variation of $1 \%$ in the number of searches for bitcoin crash is followed in the following period by a decrease of $0.06 \%$ in the price when only short term is analyzed.

Based on Fig. 4, it is inferred that a 100\% shock on lnbtc generates an increasing impulse response at lnprice, being around $2 \%$ in the second week, a result similar to that was obtained by Kristoufek (2013). A 100\% boost of lncrash, in turn, causes a response negative around $2 \%$ in the price in the first 2 weeks. A shock at $100 \%$ indicates a positive response for lnbtc and lncrash, reaching about 15\% in the third week.

The histogram of the residuals of the model shows a concentration of the near zero observations with progressive reduction of the frequency along the tails. In order to verify the existence of serial correlation in the residuals of the model, the tests of Portmanteau (2006) (PT) and Breusch (1978) \& Godfrey (1978) were applied. The test results showed that the null hypothesis of no serial correlation cannot be rejected at the significance level of $5 \%$. For stability analysis of the model, the eigen values were obtained and they are contained within the unit circle, confirming the stability of the model.

Table 5 Determination of the coefficient of each variable of VECM regressions

\begin{tabular}{|c|c|c|c|c|c|c|}
\hline \multirow[t]{2}{*}{ Variable } & \multicolumn{2}{|c|}{$\Delta$ Inpreço $_{t}\left({ }^{1}\right)$} & \multicolumn{2}{|l|}{$\Delta \operatorname{lnbtc}_{\mathrm{t}}\left({ }^{2}\right)$} & \multicolumn{2}{|c|}{$\Delta$ Incrash $_{\mathrm{t}}\left({ }^{3}\right)$} \\
\hline & Coef. & $\operatorname{Pr}(>|t|)$ & Coef. & $\operatorname{Pr}(>|t|)$ & Coef. & $\operatorname{Pr}(>|t|)$ \\
\hline a1 & $-0.03^{*}$ & 0.021 & $0.09^{* * *}$ & 0.000 & -0.06 & 0.191 \\
\hline$a 2$ & -0.02 & 0.483 & 0.09 & 0.061 & $-0.60^{* * *}$ & 0.000 \\
\hline crisis & $0.09^{*}$ & 0.043 & 0.10 & 0.215 & 0.15 & 0.373 \\
\hline$\Delta$ lnprice $_{\mathrm{t}-1}$ & $0.34^{* * *}$ & 0.000 & $0.92^{* * *}$ & 0.000 & $0.96^{* * *}$ & 0.000 \\
\hline$\Delta$ lncrash $_{\mathrm{t}-1}$ & $-0.06^{* *}$ & 0.001 & -0.07 & 0.064 & $-0.19^{*}$ & 0.019 \\
\hline$\Delta \mathrm{nbtc}_{\mathrm{t}-1}$ & 0.07 & 0.061 & -0.05 & 0.475 & -0.01 & 0.944 \\
\hline constant & $0.09^{* *}$ & 0.004 & $-0.27^{* * *}$ & 0.000 & $-0.25^{*}$ & 0.050 \\
\hline
\end{tabular}

significance level: ${ }^{* * * \prime \prime} 0.001^{* * * \prime} 0.01^{* * \prime} 0.05 "{ }^{\prime \prime} 0.1^{\prime \prime} 1$

(') Adj. $R^{2}=27.07 \%$ ( $\left.{ }^{2}\right)$ Adj. $R^{2}=20.43 \%$ ( (3) Adj. $R^{2}=34.18 \%$ 
Table 6 Granger causality test

\begin{tabular}{lll}
\hline Null hypothesis $(\mathrm{Ho})$ & F Test & $P$-value \\
\hline$X_{2}$ does not Granger-cause $X_{1}$ & 14.79 & 0.0000 \\
$X_{1}$ does not Granger-cause $X_{2}$ & 7.43 & 0.0000 \\
\hline
\end{tabular}

\section{Analysis by currency}

The procedure applied to BCX can be replicated to local prices specified by each sovereign currency. The objective is to check if prices traded in different currencies are also influenced by the structure of the global variables previously established. Only price observations are altered, which will be denominated in each respective currency. The expectation is that world events consistently impact the price at local brokerages.

Table 7 presents the coefficients of the cointegration matrix $\beta_{1}$ and $\beta_{2}$ of the error correction term by sovereign currency. The analysis by sovereign currency reiterates the behavior of the global analysis; it means that an increase of $\operatorname{lnbtc}_{\mathrm{t}-1}$, unaccompanied in the same proportion by $\operatorname{lnprice}_{\mathrm{t}-1}$ and $\operatorname{lncrash}_{\mathrm{t}-1}$, brings a pressure on $\Delta \ln$ price $\mathrm{t}_{\mathrm{t}}$, so that in the following period the price variation also increases, considering that $\alpha_{1}$ and $\alpha_{2}$ have a negative sign (Table 8 ).

On the other hand, a sudden increase of $\operatorname{lncrash}_{\mathrm{t}-1}$ generates a positive error which, when multiplied by $\alpha_{2}$, generates a decrease of $\Delta$ lnprice.

The coefficients for the variable $\Delta \operatorname{lnbtc}_{\mathrm{t}-1}$ in the equation $\Delta \ln _{\text {price }}$ are positive for all currencies and are significant at the level of $5 \%$ for six of twelve. The coefficients for the variable $\Delta \operatorname{lncrash}_{\mathrm{t}-1}$ are also significant at the $5 \%$ level for nine of twelve and, as expected, are all negative.

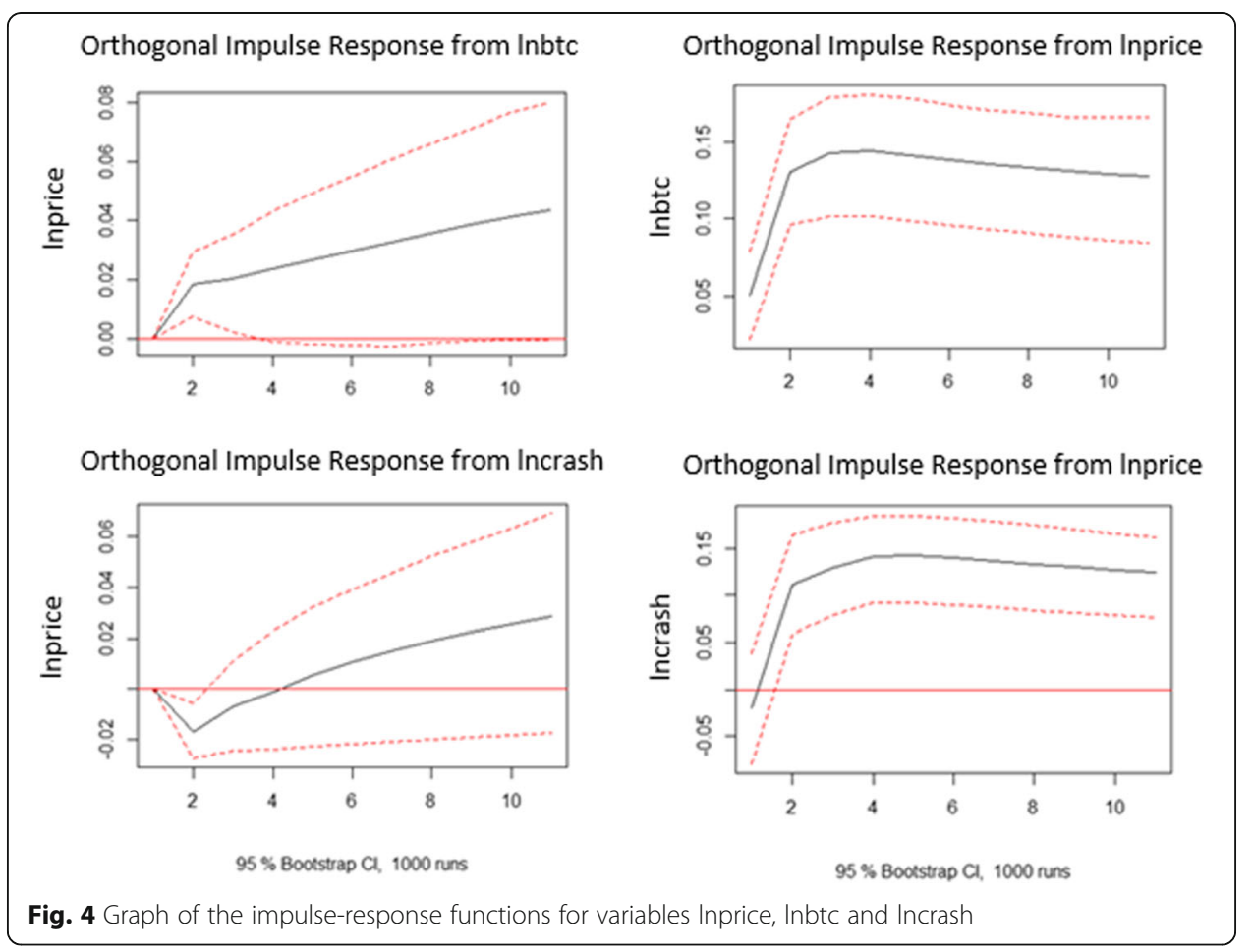


Table 7 Coefficients of the cointegration matrix $(\beta)$ of the error correction term by sovereign currency

\begin{tabular}{|c|c|c|c|c|c|c|c|c|c|c|c|c|c|}
\hline & & AUD & BRL & CAD & CNY & EUR & GBP & IDR & JPY & KRW & PLN & RUB & USD \\
\hline \multirow[t]{3}{*}{$\overline{\beta 1}$} & Inprice $:-1$ & 1.00 & 1.00 & 1.00 & 1.00 & 1.00 & 1.00 & 1.00 & 1.00 & 1.00 & 1.00 & 1.00 & 1.00 \\
\hline & Incrasht-1 & - & $2.94^{\star \star \star \star}$ & - & - & - & - & $2.6^{\star \star \star \star x}$ & - & $2.37^{\star \star \star \star}$ & - & - & $4.91^{\star \star \star}$ \\
\hline & Inbtc $_{t-1}$ & $-1.64^{\star * *}$ & $-4 \cdot 3^{\star \star \star x}$ & $-1.67^{\star \star \star \star x}$ & $-2.22^{\star \star \star *}$ & $-1.73^{\star \star \star x}$ & $-1.79^{\star \star \star x}$ & $-3.99^{\star \star \star x}$ & $-1.73^{\star \star \star \star}$ & *-3.72 & $-1.73^{\star \star \star}$ & $-1.91^{* * x}$ & *-6.54** \\
\hline \multirow[t]{3}{*}{$\overline{\beta 2}$} & Inprice $t-1$ & - & - & - & - & - & - & - & - & - & - & - & - \\
\hline & Incrasht-1 & 1.00 & - & 1.00 & 1.00 & 1.00 & 1.00 & - & 1.00 & - & 1.00 & 1.00 & - \\
\hline & Inbtc $_{t-1}$ & $-0.92^{* * *}$ & - & $-0.91^{* \star * x}$ & $-0.64^{* \star *}$ & $-0.88^{\star * *}$ & $-0.87^{\star \star x}$ & - & $-0.88^{\star \star \star *}$ & - & $-0.88^{\star \star \star}$ & $-0.87^{\star \star *}$ & - \\
\hline
\end{tabular}

The coefficient of the dummy variable crisis is significant at the level of $5 \%$ for eight currencies and positive for all of them; that is, there is strong and recurrent evidence that the Bitcoin price traded in other sovereign currencies follows the trend and also increases when there is an increase in the search for the term crisis in the world.

\section{Conclusions}

It is possible to identify a strong relationship, in the short and long term, between the terms in Google searches and the Bitcoin price. The cointegration test of the curves performed describes a tendency of simultaneous growth or decline between them. The estimated VEC model confirms the long-term dynamics based not only on the global analysis, but on a more detailed analysis of prices negotiated in different sovereign currencies.

The result of the VEC model and the significance of the coefficients demonstrate that the increase in Bitcoin interest, as measured by the number of searches for the keyword bitcoin (bitcoin crash), is followed by an increase (fall) of Bitcoin price. The bidirectional relationship exists and demonstrates that price Granger-causes the behavior of lnbtc and lncrash, intensifying the understanding that there is a speculative driver in Bitcoin's transactions.

This research is based on previous studies that used the same methodology and similar variables of attractiveness. It is worth mentioning that a longer and more recent period of data was added, confirming the cointegration between Google Trends attractiveness data and the Bitcoin price, a hypothesis that was not confirmed initially in

Table 8 Coefficients of $\Delta$ price equation per sovereign currency

\begin{tabular}{|c|c|c|c|c|c|c|c|c|c|c|c|c|}
\hline Variable & AUD & BRL & CAD & CNY & EUR & GBP & IDR & JPY & KRW & PLN & RUB & USD \\
\hline $\mathbf{\alpha}_{1}$ & $-0.03^{* *}$ & -0.01 & $-0.02^{*}$ & -0.02 & -0.02 & $-0.02^{*}$ & -0.01 & $-0.04^{* *}$ & -0.02 & $-0.03^{*}$ & -0.02 & 0.01 \\
\hline$\alpha_{2}$ & -0.03 & & -0.02 & 0.00 & -0.01 & -0.02 & & -0.03 & & -0.02 & -0.02 & \\
\hline crisis & $0.14^{\star *}$ & 0.07 & $0.13^{\star *}$ & $0.10^{*}$ & $0.09^{*}$ & $0.12^{\star *}$ & 0.06 & 0.08 & 0.07 & $0.13^{\star *}$ & $0.10^{*}$ & $0.14^{*}$ \\
\hline$\Delta$ lnprice $_{t-1}$ & $0.31^{* * *}$ & $0.52^{* * *}$ & $0.35^{\star * *}$ & $0.40^{* * *}$ & $0.41^{* * *}$ & $0.36^{* * *}$ & $0.38^{* * *}$ & $0.34^{\star \star *}$ & $0.34^{* * *}$ & $0.31^{* \star *}$ & $0.39^{* \star *}$ & $0.16^{*}$ \\
\hline$\Delta$ lncrash $_{\mathrm{t}-1}$ & $-0.07^{* *}$ & -0.03 & $-0.06^{* *}$ & $-0.09^{* * *}$ & $-0.05^{* *}$ & $-0.06^{* *}$ & -0.02 & $-0.08^{* * *}$ & -0.02 & $-0.07^{\star *}$ & $-0.06^{* *}$ & $-0.07^{*}$ \\
\hline$\Delta \operatorname{lnbtc}_{\mathrm{t}-1}$ & $0.11^{* *}$ & 0.06 & $0.08^{*}$ & 0.04 & 0.07 & 0.08 & 0.03 & $0.11^{*}$ & 0.04 & $0.10^{*}$ & $0.08^{*}$ & $0.14^{* *}$ \\
\hline$\Delta$ lnprice $_{\mathrm{t}-2}$ & & & & & & & & & & & & 0.06 \\
\hline$\Delta$ lncrash $_{\mathrm{t}-2}$ & & & & & & & & & & & & -0.03 \\
\hline$\Delta \operatorname{lnbtc}_{\mathrm{t}-2}$ & & & & & & & & & & & & $015^{\star *}$ \\
\hline constant & $0.10^{* *}$ & 0.03 & $0.09^{* *}$ & 0.08 . & $0.07^{*}$ & $0.07^{\star *}$ & 0.14 & $0.31^{* *}$ & 0.18 & $0.12^{* *}$ & $0.12^{*}$ & $0.03^{* *}$ \\
\hline Adj. R2 & $28.82 \%$ & $35.25 \%$ & $28.64 \%$ & $27.74 \%$ & $30.19 \%$ & $27.63 \%$ & $22.09 \%$ & $27.69 \%$ & $17.74 \%$ & $26.68 \%$ & $30.97 \%$ & $15.26 \%$ \\
\hline F-Test & $16.44^{* * *}$ & $23.23^{\star * *}$ & $16.31^{\text {*** }}$ & $14.21^{\text {***}}$ & $17.56^{\star \star *}$ & $15.62^{* * *}$ & $10.83^{* \star *}$ & $15.33^{* \star *}$ & $9.15^{\star \star *}$ & $14.93^{* \star *}$ & $18.17^{\text {***}}$ & $6.34^{* \star *}$ \\
\hline Note: sig & ificance & level: ‘* & $* * * \prime 0.0$ & $01^{* * * \prime} 0$ & $0.01^{\prime * \prime}$ & $0.05 \because 0$ & $0.1{ }^{\prime \prime} 1$ & & & & & \\
\hline
\end{tabular}


Kristoufek's study (2013), which took into account a historical database between May 2011 and June 2013.

The crisis variable is useful for investment decision-making. In times of high demand for news about a world economic crisis, there is an increase in the Bitcoin price, which may be related to a greater demand for the virtual currency and its characteristics that are favorable to these moments, such as low probability of being confiscated, high security, and high portability that allows bitcoins to be transferred globally in minutes. Bitcoins priced in different sovereign currencies follow global price behavior and are quickly adjusted by changing interest in currencies around the world and by crisis events.

The findings may show to policymakers and monetary authorities that society is afraid about losing their purchasing power in period of crisis, so people are looking for buying safe haven assets, and Bitcoin might be one of them. Understanding these interests is fundamental to investors, who want to diversify their portfolio, and to governments, which can establish alternatives to avoid having their currencies depreciated against Bitcoin.

\begin{abstract}
Abbreviations
ADF: Augmented Dickey Fuller Test; AIC: Akaike Information Criterion; AUD: Australian Dollar; BCX: Bitcoin.com Composite Price Index; BG: Breusch-Godfrey; BRL: Brazilian Real; BTC: Bitcoin; CAD: Canadian Dollar; CEO: Chief Executive Officer; CNY: Yuan Renminbi; CPI: Consumer Price Index; DJIA: Dow Jones Industrial Average; EUR: Euro; FFR: Federal Funds Rate; FPE: Final Prediction Error; FTSE: Financial Times Stock Exchange; GBP: Pound Sterling; GP: Gold Price; HQ: Hannan-Quinn; IDR: Indonesian Rupiah; IMF: International Monetary Fund; JPY: Japanese yen; KRW: South Korean Won; PLN: Polish Zloty; PT: Portmanteau; RUB: Russian Ruble; SC: Schwarz; USA: United States of America; USD: United States Dollar; USDI: US Dollar Index; VAR: Vector Autoregressive; VEC: Vector Error Correction; VECM: Vector Error Correction Model
\end{abstract}

Acknowledgements

My advisor, Professor Ricardo Masini, helped and gave me the support to guarantee the technical quality of this research.

\title{
Authors' contributions
}

The author(s) read and approved the final manuscript.

\section{Funding}

I know of no conflicts of interest associated with this publication, and there has been no financial support for this work that could have influenced its outcome. There is no conflict of competing interests.

\section{Availability of data and materials}

The selected database to be considered by the model was found in three electronic data sources: Google Trends (https://trends.google.com/trends/), Bitcoincharts (https://bitcoincharts.com/charts/) and Bitcoin.com (https://charts. bitcoin.com/btc/chart/price). The period studied is the weeks between December 17, 2012 and February 12, 2018. The database starts in December 2012 due to a technical limitation of Google Trends; until that date, the tool produced weekly observations, while the extended period generates monthly observations.

\section{Competing interests}

The authors declare that they have no competing interests.

Received: 17 April 2019 Accepted: 11 February 2020

Published online: 13 April 2020

\section{References}

Akaike H (1969) Fitting autoregressive models for prediction. Ann Inst Stat Math 21:243-247

Al-Khazali O, Bouri E, Roubaud D (2018) The impact of positive and negative macroeconomic news surprises: gold versus Bitcoin. Econ Bull, AccessEcon 38:373-382

Bacen. Comunicado n 31.379, de 16 de novembro de 2017. Alerta sobre os riscos decorrentes de operações de guarda e negociação das denominadas moedas virtuais. http:/www.bcb.gov.br/pre/normativos/busca/normativo.asp?numero=313 79\&tipo=Comunicado\&data=16/11/2017, visited on 7 May 2018

Balcilar M et al (2017) Can volume predict bitcoin returns and volatility? A quantiles-based approach. Econ Model https://ssrn. com/abstract=2938555, visited on 12 Dec 2017

Bitcoin.com. Bitcoin core (BTC) price. https://charts.bitcoin.com/btc/chart/price, visited on 1 March 2018 
Bitcoincharts. Pricechart. https://bitcoincharts.com/charts/bitstampUSD\#rg60ztgSzm1g10zm2g25zv, visited on 1 March 2018 Bouoiyour J, Selmi R (2015) What does bitcoin look like? Ann Econ Financ 16:449-492

Bouri E, Gil-Alana L, Gupta R, Roubaud D (2018) Modelling long memory volatility in the Bitcoin market: evidence of persistence and structural breaks. Int J Finance Econ

Bouri E et al (2017) Bitcoin for energy commodities before and after the December 2013 crash: diversifier, hedge or safe haven? Appl Econ https://ssrn.com/abstract=2925783, visited on 20 Dec 2017

Breusch TS (1978) Testing for autocorrelation in dynamic linear models. Aust Econ Pap 17:334-355

Buchholz M, Delaney J, Warren J, Parker J (2012) Bits and bets, information, price volatility, and demand for bitcoin. Economics 312

Bueno RLS (2015) Econometria de séries temporais. Cengage Learning, Sao Paulo

Buterin V (2013) The bitcoin crash: an examination. Bitcoin Magazine, Nashville https://bitcoinmagazine.com/articles/thebitcoin-crash-an-examination-1365911041/, visited on 3 June 2018

Chao X, Kou G, Peng Y, Alsaadi FE (2019) Behavior monitoring methods for trade-based money laundering integrating macro and micro prudential regulation: a case from China. Technol Econ Dev Econ 25(6):1081-1096

Ciaian P, Miroslava R, Kancs D (2016a) Can bitcoin become a global currency? IseB 14:883-919

Ciaian P, Miroslava R, Kancs D (2016b) The economics of bitcoin price formation. Appl Econ 48:1799-1815

Civitarese JM (2018) Does metcalfe's law explain bitcoin prices? A time series analysis. SSRN Electronic Journal

Davies DC (2014) The curious case of bitcoin: is bitcoin volatility driven by online search? University of Victoria, Victoria

Dyhrberg AH (2016) Hedging capabilities of bitcoin. Is it the virtual gold? Financ Res Lett 16:139-144

Engle RF, Granger CWJ (1987) Co-integration and error correction: representation, estimation and testing. Econometrica 55: $251-276$

G1. Crise da Grécia: veja perguntas e respostas e o que acontece agora. http://g1.globo.com/economia/noticia/2015/07/criseda-grecia-veja-perguntas-e-respostas-e-o-que-acontece-agora.html, visited on 22 June 2018

Gandal N et al (2018) Price manipulation in the bitcoin ecosystem. J Monet Econ 95:86-96

Godfrey LG (1978) Testing for higher order serial correlation in regression equations when the regressors include lagged dependent variables. Econometrica 46:1303-1313

Google Trends. https://trends.google.com/trends/?geo=US, visited on 1 Mar 2018

Hannan E, Quinn B (1979) The determination of the order of an autoregression. J R Stat Soc:190-195

Hayes A (2017) Cryptocurrency value formation: an empirical analysis leading to a cost of production model for valuing bitcoin. Telematics Inform. https://doi.org/10.2139/ssrn.2648366 visited on 25 Jan 2018

Johansen S (1988) Statistical analysis of Cointegrating vectors. J Econ Dyn Control 12:231-254

Kwan C. How the Greece debt crisis showed the world that bitcoin is a store of value. https://cointelegraph.com/news/howthe-greece-debt-crisis-showed-the-worldthat-bitcoin-is-a-store-of-value, visited on 22 June 2018.

Kelion L Bitcoin sinks after China restricts yuan exchanges. http://www.bbc.com/news/technology-25428866, visited on 3 June 2018

Kim YB et al (2017) When bitcoin encounters information in an online forum: using text mining to analyse user opinions and predict value fluctuation. PLOS ONE 12

Kristoufek L (2013) Bitcoin meets google trends and wikipedia: quantifying the relationship between phenomena of the Internet era. Sci Rep 3

Kristoufek $L$ (2015) What are the main drivers of the bitcoin price? Evidence from wavelet coherence analysis. PLoS ONE Nakamoto, S. (2008) Bitcoin: a peer-to-peer electronic cash system. https://bitcoin.org/bitcoin.pdf , visited on 15 Oct 2017

Nasir M, Huynh D, Nguyen P, Duong D (2019) Forecasting cryptocurrency returns and volume using search engines. Financ Innov

Pagliery J Greeks are rushing to bitcoin. http://money.cnn.com/2015/06/29/technology/greece-bitcoin/index.html, visited on 22 June 2018

Pfaff B (2006) Analysis of integrated and Cointegrated time series with R. Springer, NY

Polasik M et al (2015) Price fluctuations and the use of Bitcoin: an empirical inquiry. Int J Eletron Commerce 20:9-49

Reuters. China bans banks from bitcoin transactions. https://www.smh.com.au/business/markets/china-bans-banks-frombitcoin-transactions-20131206-2yugy.html, visited on 3 June 2018

Rosenfeld E Greek crisis stokes bitcoin prices higher. https://www.cnbc.com/2015/06/29/greek-crisis-stokes-bitcoin-priceshigher.html, visited on 22 June 2018

S Kumar A, Ajaz T (2019) Co-movement in crypto-currency markets: evidences from wavelet analysis. Financ Innov 5:33. https://doi.org/10.1186/s40854-019-0143-3

Schwarz G (1978) Estimating the dimension of a model. Ann Stat 6:461-464

Van Wijk D (2013) What can be expected from the BitCoin? Erasmus Rotterdam Universiteit, Rotterdam

Wooldridge JM (2006) Introdução à Econometria - uma abordagem moderna. Thomson

Xu M, Chen X, Kou G (2019) A systematic review of blockchain. Financ Innov 5:27. https://doi.org/10.1186/s40854-019-0147-z Yermack D (2015) Is bitcoin a real currency? An economic appraisal, pp 31-43

Zhu Y, Dickinson D, Li J (2017) Analysis on the influence factors of Bitcoin's price based on VEC model. Financ Innov

\section{Publisher's Note}

Springer Nature remains neutral with regard to jurisdictional claims in published maps and institutional affiliations. 